\title{
The classification of arabica gayo wine coffee using UV-visible spectroscopy and PCA-DA method
}

\author{
Diding Suhandy ${ }^{1, *}$, and Meinilwita Yulia $^{2}$ \\ ${ }^{1}$ The University of Lampung, Faculty of Agriculture, Department of Agricultural Engineering, Spectroscopy Research Group (SRG), \\ Laboratory of Bioprocess and Postharvest Engineering, Jl. Prof. Dr. Soemantri Brojonegoro No.1, Bandar Lampung, 35145, Indonesia \\ ${ }^{2}$ Lampung State Polytechnic, Department of Agricultural Technology, Jl. Soekarno Hatta No. 10, Rajabasa Bandar Lampung, 35141 , \\ Indonesia
}

\begin{abstract}
The unique processing of Arabica Gayo Wine coffee produces special attributes to the beverage and could increase its value. However, it is important to prove the authenticity of Arabica Gayo Wine coffee using reliable methods. The objective of this study was to evaluate the potential of UV-visible spectroscopy and principal component analysis-discriminant analysis (PCA-DA) method for classification of ground roasted Arabica Gayo Wine coffee. A number of 200 samples of Arabica Gayo Wine coffee and 200 samples of Arabica Gayo normal (not Wine) coffee was used. The spectral data obtained in the UV-visible region were analyzed using PCA-DA with standard normal variate (SNV) and followed by Savitzky-Golay smoothing with different number of smoothing point (NSP). The results showed that the best PCA-DA model was obtained with NSP $=23$ with coefficient of determination for calibration $\left(\mathrm{R}^{2}\right)=0.99$, root mean square error of calibration $($ RMSEC) $=0.005692$ and root mean square error of validation $($ RMSEV) $=$ 0.006112. Using this model, a good classification between Gayo Wine and Gayo normal in prediction step was achieved with $100 \%$ accuracy, sensitivity and specificity. Thus, the proposed method can be used for the evaluation of authenticity of ground roasted Arabica Gayo Wine coffee.
\end{abstract}

\section{Introduction}

Gayo Arabica coffee from Aceh, Indonesia is one of the important and most expensive specialty coffees in Indonesia. In 2016, the total production of Gayo Arabica coffee in Aceh province (central Aceh, Bener Meriah and Gayo Lues region) is about 47 thousand tons (total national coffee production is about 639 thousand tons) [1]. Now, Aceh is the second largest production area for Arabica coffee in Indonesia [1-2].

Recently, a special production of Gayo Arabica coffee from Takengon, Aceh with several time of fermentation called as Gayo Wine coffee is becoming popular. This coffee has a unique taste and high in price. The popularity and limited supply of Gayo Wine coffee makes it very vulnerable to fraudulent [3].

In practice, it is not easy to discriminate ground roasted Gayo Wine and Gayo normal (not Wine) coffee by naked eyes. As shown in Fig. 1, visible inspection of the two coffee is not reliable. For this reason, it is desired to develop a new analytical method to discriminate Gayo Wine and Gayo normal in ground roasted coffee. Among the available and possible analytical method, UV-visible spectroscopy is preferable due to its several advantages: low cost spectrometer, easy to use and to do maintenance of spectrometer, freechemical waste and the spectrometer is available and accessible in most laboratory in Indonesia [4].
In previous studies, UV-visible spectroscopy has been used to discriminate ground roasted pure peaberry coffee and pure normal coffee [4], to discriminate ground roasted civet and non-civet coffee [5], and to quantify the degree of adulteration in ground roasted civet coffee [6]. Discrimination of several Indonesian specialty coffees has been investigated using Fluorescence spectroscopy [7] and NIR spectroscopy [8]. However, to the best of our knowledge, there is no any report on the use of UV-visible spectroscopy for discrimination ground roasted Gayo Wine and Gayo normal coffee. Therefore, the objective of this study is to evaluate the potential of UV-visible spectroscopy combined with chemometric method to discriminate pure ground roasted Gayo Wine and Gayo normal coffee.

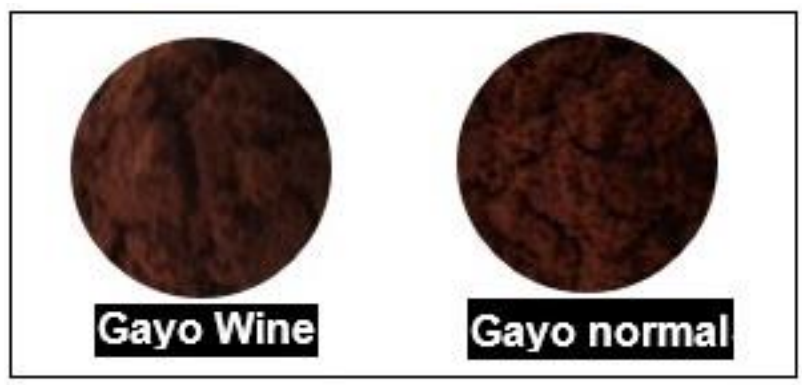

Fig. 1. Ground roasted Arabica Gayo Wine and Gayo normal.

\footnotetext{
* Corresponding author: diding.sughandy@,fp.unila.ac.id
} 


\section{Materials and method}

\subsection{Coffee samples}

Ground roasted Arabica Gayo Wine and Gayo normal coffee were purchased from local market in Banda Aceh, Indonesia and transported to Bandar Lampung. A total of 200 pure Gayo Wine and 200 pure Gayo normal samples were used. Each sample has 1 gram pure Gayo Wine or Gayo normal ground roasted coffee. Sample preparation including sieving and grinding was done based on previous reported studies [4-6].

Spectral data acquisition was done on aqueous coffee samples. For this, an extraction of coffee samples were performed based on previous researches [4-6].

\subsection{Spectral measurement}

UV-visible spectral data measurements were performed with a Genesys 10s UV-Vis Spectrometer (Thermo Fisher Scientific, USA) equipped with a $10 \mathrm{~mm}$ quartz cell. Spectral measurements were recorded in the range of 190-1100 nm with $1 \mathrm{~nm}$ resolution. Distilled water was used for blank measurement.

\subsection{Chemometrics}

Prior to classification analysis (both unsupervised and supervised methods), spectra pre-processing was performed. There were two pre-processing methods applied to improve the quality of spectral data: standard normal variate (SNV) and Savitzky-Golay (SG) smoothing with different number of smoothing point (NSP). SNV is used to remove both an additive and multiplicative noise due to scatter interference [9-11]. SNV has been used for many spectrometric application and can improve the prediction accuracy [9]. In practice, SNV was done by subtracting the mean from an individual spectrum and divides it by its standard deviation [12]. SG smoothing is a widely used preprocessing method that can effectively eliminate noises like baseline-drift, tilt and reverse [10].

Principal component analysis (PCA) is one of the unsupervised methods used for dimensionality reduction by converting a number of correlated variables into fewer variables called principal components (PCs). In this study, PCA was used for clustering of samples and detecting the occurrence of outliers. Classification model to discriminate between Gayo Wine and Gayo normal was developed by using principal component analysisdiscriminant analysis PCA-DA. This method worked based on principal component regression (PCR) algorithm with a dummy response variables $(\mathrm{y}=1$ for Gayo Wine and $\mathrm{y}=0$ for Gayo normal). For more detail about PCA and PCR, several previous published paper were suggested [13-14]. For PCA-DA model development, samples were divided randomly into three sets: calibration samples set (232 samples), validation sample set (112 samples) and prediction sample set (56 samples). To evaluate the classification performance of the PCA-DA model, three commonly parameters were used: overall accuracy, sensitivity and specificity. The calculation of those parameters was done based on previous published work [11].

\subsection{Software}

The standard multivariate analysis package, The Unscrambler $\mathrm{X}$ version 10.4 (free trial version, 30 days, CAMO, Oslo, Norway) was used for the data analysis including pre-processing spectra, PCA and PCA-DA.

\section{Results and discussion}

\subsection{Analysis of spectral data}

Figure 2 shows the average spectra of Gayo Wine and Gayo normal coffee samples in the range of 190-1100 $\mathrm{nm}$. The most informative spectral region was identified in the range of $250-450 \mathrm{~nm}$. In the initiation of spectral data, a relatively noisy data was observed and spectral region more than $450 \mathrm{~nm}$ is almost no absorbance could be detected (almost zero absorbance). Figure 3 shows the average pre-processed spectra in the range of 250-450 $\mathrm{nm}$. The pre-processing methods are combination of standard normal variate and Savitzky-Golay smoothing $(\mathrm{NSP}=3)$. It is also said that a spectral difference was observed in the region of $250-450 \mathrm{~nm}$.

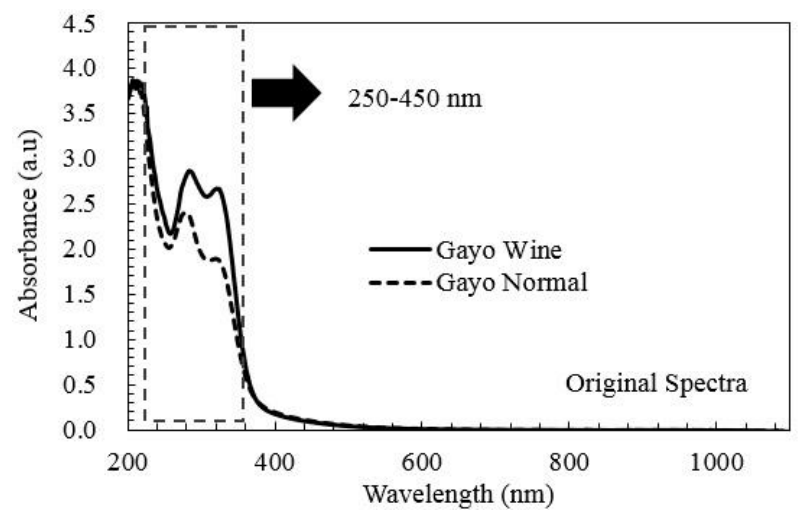

Fig. 2. Original spectra of Gayo Wine and Gayo normal (average) in the range of 190-1100 nm.

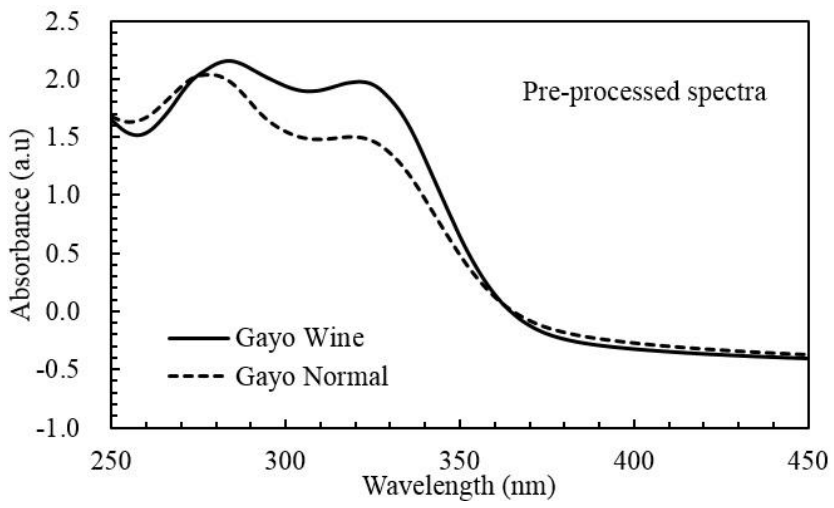

Fig. 3. Pre-processed spectra of Gayo Wine and Gayo normal (average) in the range of $250-450 \mathrm{~nm}$. 


\subsection{Principal component analysis (PCA)}

In order to see the clustering of all samples, PCA was performed for 400 samples (200 samples Gayo Wine and 200 samples Gayo normal) with full cross-validation method using spectral data $250450 \mathrm{~nm}$. The result of PCA was depicted in Fig. 4. The score plot of the first two principal components (PCs) clearly shows that Gayo Wine and Gayo normal samples were well-separated along PC1: Gayo normal samples have negative PC1 scores, whereas Gayo Wine samples have positive PC1 scores. The PC1 scores alone accounted for more than $90 \%$ of the spectral data and the cumulative percent variance (CPV) of the first two principal components (PC1+PC2) was found to be $97 \%$ of the total variance in the spectral datasets.

To determine the important wavelengths which is responsible for the separation between Gayo Wine and Gayo normal coffee samples, a plot of $\mathrm{x}$-loadings versus wavelengths was investigated and the result was showed in Fig. 5. Wavelengths with high loading values are the most important variables for separation between Gayo Wine and Gayo normal coffee. Two wavelengths at 262 $\mathrm{nm}$ and $325 \mathrm{~nm}$ were observed with high negative and positive loadings, respectively. Those wavelengths were correspond with the absorbance of caffeine and trigonelline in coffee, respectively [4-6].

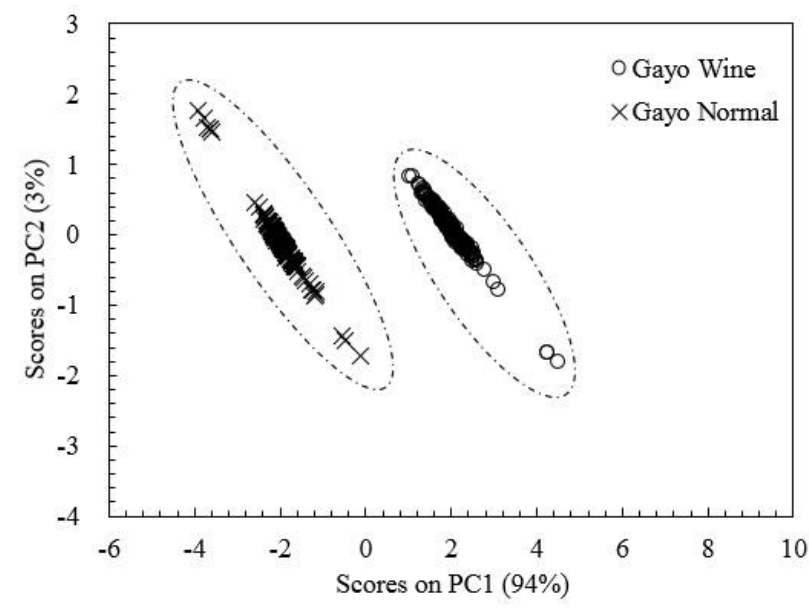

Fig. 4. Principal component analysis plot of $\mathrm{PC} 1$ and $\mathrm{PC} 2$ of Gayo Wine and Gayo normal in the range of 250-450 nm.

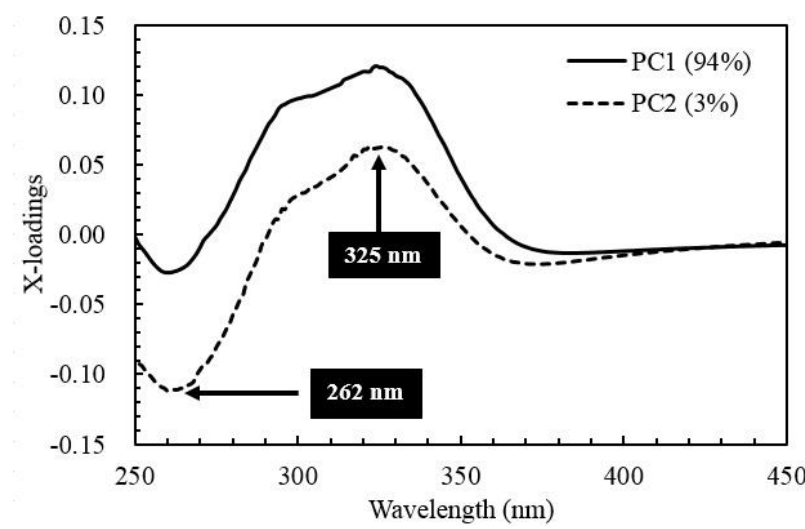

Fig. 5. The $x$-loadings versus wavelength of first two principal components (PC1 and $\mathrm{PC} 2$ ) in the range of 250-450 $\mathrm{nm}$.

\subsection{Development of PCA-DA classification model}

The PCA-DA model was developed using pre-processed spectra (combination of SNV+SG smoothing). In the SG smoothing, there are many different parameters include polynomial degree (PD), the derivative order of polynomial (DOP) and the number of smoothing points (NSP) or the size of smoothing window (SW) [15]. A too-small NSP is prone to cause calculation error, resulting in a decreased model precision, while a toolarge NSP would over smooth the spectral data, most of the information were missing and leading to decreased accuracy of model [15]. For this reason, it is important to select an appropriate NSP for SG smoothing. Figure 6 shows the plot between NSP and root mean square error of validation (RMSEV). The NSP $=23$ was corresponding with the lowest $\mathrm{RMSEV}=0.006112$. This PCA-DA model has 15 latent variables (LVs), high coefficient of determination $\left(\mathrm{R}^{2}=0.99\right)$ and low root mean square error of calibration $($ RMSEC $=0.005692)$. This PCA-DA model with NSP $=23$ was selected for the best classification model to discriminate Gayo Wine and Gayo normal ground roasted coffee.

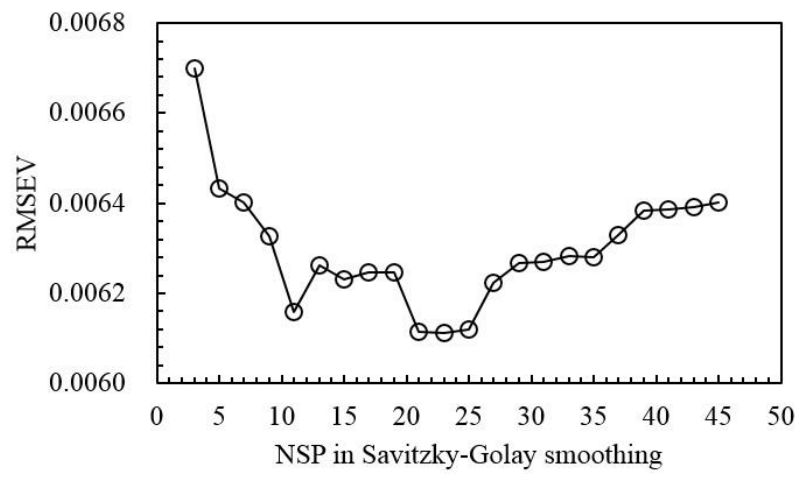

Fig. 6. Plot of NSP versus RMSECV in validation step.

The best PCA-DA model was presented in plot of samples versus y-predicted values both for calibration (Fig. 7) and validation (Fig. 8) ( $\mathrm{y}=1$ for Gayo Wine and $\mathrm{y}=0$ for Gayo normal). The threshold value is 0.5 line. It shows that all samples in calibration and validation are located very close to its class resulted in $100 \%$ of accuracy, sensitivity and specificity.

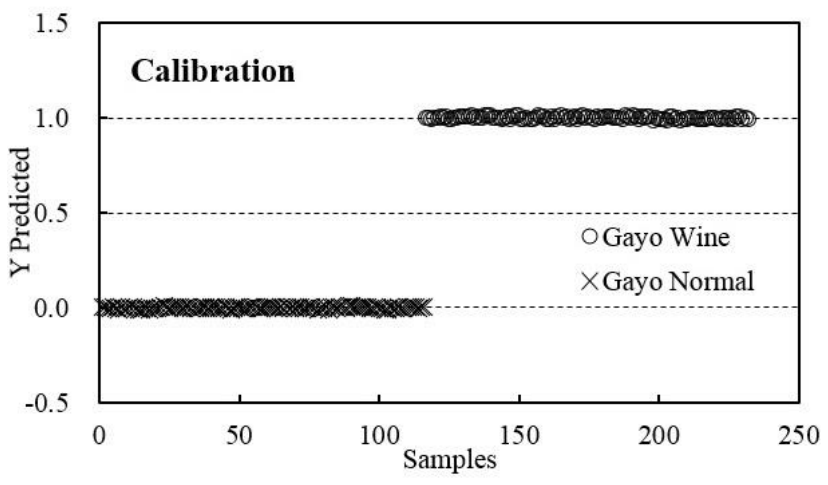

Fig. 7. PCA-DA classification model in calibration step. 


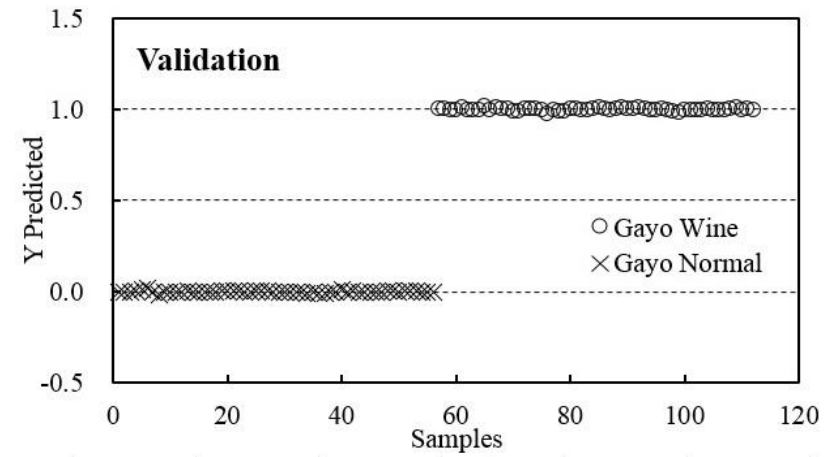

Fig. 8. PCA-DA classification model in validation step.

Our result was comparable to previous reported studies. Marquetti et al. studied the discrimination of several Arabica coffees based on its geographic and genotypic origin using NIR spectroscopy. The sensitivity was $75-100 \%$ for geographic and genotypic discrimination [16]. Suhandy and his co-workers has developed model discrimination for several Indonesian specialty using UV-visible spectroscopy and chemometric methods with $100 \%$ of accuracy, sensitivity, and specificity: peaberry vs. normal coffee [4] and civet vs. non-civet coffee [5].

\subsection{Blind classification using PCA-DA model}

To evaluate the predictive ability of the developed PCADA model in classification of Gayo Wine and Gayo normal, 56 samples (28 samples for Gayo wine and 28 samples for Gayo normal, respectively) which is not used in model development was tested. The result was depicted in Fig. 9. It is clear that all prediction samples are lied in its proper class. All Gayo normal samples were close to $\mathrm{y}=0$ and all Gayo Wine samples were close to $y=1$. Thus, the accuracy, sensitivity and specificity of $100 \%$ was also obtained in prediction.

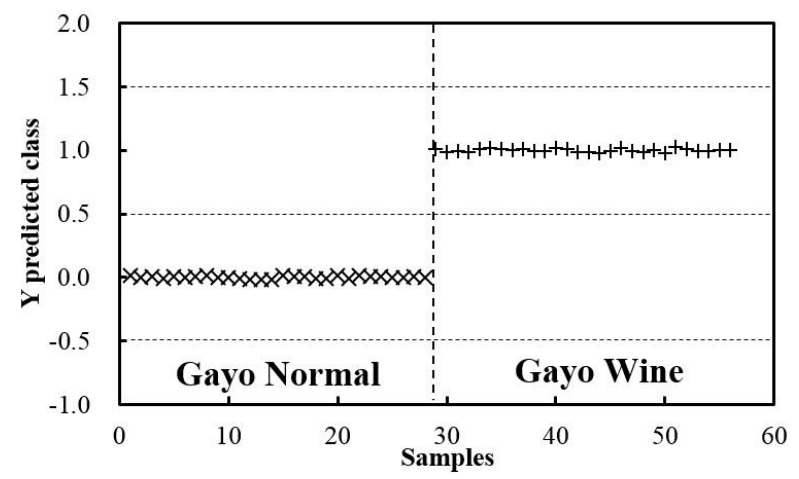

Fig. 9. PCA-DA classification result using prediction set.

\section{Conclusions}

This study has revealed that UV-visible spectroscopy combined with PCA-DA method has potential for discrimination of Gayo Wine and Gayo normal ground roasted coffee. The developed PCA-DA model is able to predict the class of Gayo Wine and Gayo normal with
$100 \%$ of accuracy, sensitivity and specificity. This method can be implemented as simple, consistent and green technology to allow us to discriminate Gayo Wine and Gayo normal. In the near future, this kind of technology is needed to develop an authentication system of Indonesian specialty coffee.

The authors thank the University of Lampung and the Indonesian Ministry of Research, Technology and Higher Education (Kemenristekdikti) for funding this research under Research Grant PENELITIAN STRATEGIS NASIONAL INSTITUSI (PSNI) [grant No. 393/UN26.21/PN/2018].

\section{References}

1. A.A. Susanti, B. Waryanto (Ed.) Agricultural Statistics $2017 \quad$ (2017) Retrieved from http://epublikasi.setjen.pertanian.go.id/download/file 367-statistik-pertanian-2017.

2. Pedoman Teknis Pengembangan Kopi (2014) Retrieved from http://www.ditjenbun.pertanian.go.id/ Accessed 25.05 .2018

3. L.K. Nasution, M. fahrur, Christine, Imaduddin, Wardayani, JOJAPS, 10, 82 (2017)

4. D. Suhandy, M. Yulia, Int. J. Food Prop. 20, S331 (2017)

5. M. Yulia, D. Suhandy, J. Phys.: Conf. Ser., 835 012010 (2017)

6. D. Suhandy, M. Yulia, Int. J. Food Sci. (2017)

7. D. Suhandy, M. Yulia, IOP Conf. Ser.: Mater. Sci. Eng. 334012059 (2018)

8. M. Yulia, D. Suhandy, IOP Conf. Ser.: Mater. Sci. Eng. 334012062 (2018)

9. C.L. Cunha, A.S. Luna, R.C.G. Oliveira, G.M. Xavier, M.L.L. Paredes, A.R. Torres, Fuel, 204, 185 (2017)

10. Å. Rinnan, F. van den Berg, S. B. Engelsen, TrAC Trends Anal. Chem. 28, 1201 (2009)

11. G.F. Li, Q.B. Yin, L. Zhang, M. Kang, H.Y. Fu, C.B. Cai, L. Xu, Anal. Methods 9, 1897 (2017)

12. V. Cortes, A. Rodriguez, J. Blasco, B. Rey, C. Besada, S. Cubero, A. Salvador, P. Talens, N. Aleixos, J. Food Eng. 204, 27 (2017)

13. S. Wold, K. Esbensen, P. Geladi, Chemometr. Intell. Lab. Syst. 2, 37 (1987)

14. H. Abdi, L.J. Williams, WIREs Comp. Stats. 2, 433 (2010)

15. P.S. Sampaio, A. Soares, A. Castanho, A.S. Almeida, J. Oliveira, C. Brites, Food Chem. 242, 196 (2018)

16. I. Marquetti, J.V. Link, A.L.G. Lemes, M.B.S. Scholz, P. Valderrama, E. Bona, Comput Electron Agric. 121, 313 (2016) 